Father: "And then they passed him back to us, and from then on he was our baby. And he wasn't poked, prodded; there was no invasive testing done on him. All he ever knew was love and dignity, and that was very important to us...."

Mother: "And I've kept all the clothes that he wore. He had a lovely smell, that lovely newborn baby smell, which is still here with us. Then he was dressed separately to rest him. But I've got all his clothes, all the things that I made for him, because if he'd have gone into the special care baby unit I didn't want blankets and that that they'd provided. I wanted all my own stuff that I could bring home, which was important. They're your keepsakes. They're your baby. Although I haven't got my baby, I do have the clothes that he wore, and that's the best thing I'll ever get, so treasure them. Mine haven't been washed. They've still got his scent on, and they're not going anywhere, they're at home with me."

\section{Moving on together}

Although Benjamin's short journey was over, his parents' own journey continued through grief, adjustment, and the stress of the nagging question, "Why me?"

Mother: "You know, there's times we've just sobbed and cried, and it's unfair."

Father: "It is; it's unfair, it's unjust. You find yourself saying, 'What have we done to deserve this? What could we have done differently? How could we have?' You know, you get to a point where it's at the back of your mind and you're thinking, 'Well, there's an extra chromosome carried. Well, so was it mine or was it my wife's?' And there's absolutely nothing you can do about that. You don't choose which egg you release at a time or which sperm is going to win the race, do you? You have to talk; you have to tell each other how you're feeling. You have to be willing to be a punchbag every now and then, for each other...."
"It can weaken your relationship, or it can make your relationship stronger. I think if it weakens your relationship it's possibly because you're not telling each other what you're thinking. You have to talk to each other. This whole thing has been tragic enough as it is. It would have been even more tragic if it had pushed the couple apart as well. And that would be a real tragedy, because it's a shared thing that you've been through. And when you're both old bones, sat around talking about how your life's gone, you've got to look back on the bad times in your life and say, 'We did the right thing.' And I do think we could do that .... It's been hard; it's been a journey. It's been a bloody difficult journey sometimes."

Mother: "I was glad we did what we did for him."

LL thanks all the people who took part in interviews on antenatal screening experiences.

Contributors: LL conducted the interviews and wrote the article. $\mathrm{JC}$ and JC told their story and helped revise the manuscript.

Funding: The study on which this paper draws was funded by the UK National Screening Committee of the NHS.

Competing interests: None declared.

Ethical approval: The DIPEx research group has full MREC approval for its studies, reference numbers 02/5/43 (pregnancy and childbirth) and 03/5/016 (all adult health conditions). People who take part in an interview see a copy of their interview transcript and remove any material they do not want made publicly available, before giving DIPEx copyright for their words to be used in broadcasting, research, teaching, and publication. People who volunteered to take part in this study were sent a full verbatim transcript of their interview and were able to remove any sections they did not want used publicly before giving DIPEx copyright for their words to be used in broadcasting, research, teaching and publication. Names are normally removed to guarantee anonymity, although in this case the couple expressly wanted Benjamin's name to appear. A full account of our methods and ethical procedures for consent and copyright are available at www.dipex.org/aboutus_methodology.asp

1 National Electronic Library for Health. Specialist Library Clinical Genetics. Palace Syndrome http://libraries.nelh.nhs.uk/genepool/ viewResource.asp?uri $=$ http://libraries.nelh.nhs.uk/common/

resources/?id = 93804\#Find $\% 20$ out $\%$ 20more

(Accepted 30 September 2005)

\title{
A shocking affair
}

Many years ago, when I was an anaesthetic registrar, one of my duties was to visit a psychiatric hospital for the weekly outpatient list for electroconvulsive therapy. It was all fairly straightforward. The patients were mainly women in their $50 \mathrm{~s}$ or $60 \mathrm{~s}$, and there were usually six or seven at a session. The patients all sat together on benches, usually with a relative to escort them home afterwards. There were two curtained cubicles, each with a couch, facilities for ventilating the patient with oxygen, and, of course, the ECT apparatus. On the other side of the waiting area there were some curtained recovery cubicles, each with its own couch.

It was a bit of a production line system. A patient would be brought in to a cubicle, I would anaesthetise her with thiopental and suxamethonium, the psychiatrist would administer the shock, and I would ventilate the patient with oxygen until she woke up. She would then be transferred to a trolley and thence to the couch in a recovery cubicle. The nurse was then asked to bring in the next patient. And so it went on.

On one occasion, after the second or third patient, a nurse from the waiting area came in to ask if anyone knew where the previous patient's relative had got to. She had, apparently, "disappeared." It took a few minutes for the dreadful truth to become apparent. Instead of bringing in the next patient, the nurse had brought in the previous patient's relative, who had said nothing and duly undergone electroconvulsive therapy. We were all appalled and unsure what to do.

I went over to the now recovering "missing" relative to ask how she was and apologise for the error. I received a glowing response. She said she was fine, just fine; in fact, she felt much better than when she had arrived with her friend. Honesty compelled me to explain what had happened. Fortunately, those were far less litigious days, and the elderly woman was quite charming said she fully understood and insisted that it was all her own fault for not speaking up. Indeed, she added, she now felt so much better than when she had arrived at the clinic that perhaps she should have regular treatments.

John Zorab retired consultant anaesthetist, Iron Acton, Bristol (JZorab@compuserve.com) 